\title{
Prevalence of Helicobacter pylori among Peptic Ulcer Patients Attending National Hospital Abuja
}

Talabi EO ${ }^{1}$, Ajobiewe $\mathrm{HF}^{1}$, Ajobiewe $\mathrm{JO}^{2}$, Ogundeji AA ${ }^{3}$, Umeji $\mathrm{LC}^{4}$, Ajobiewe $\mathrm{DC}^{5}$

${ }^{1}$ Bingham University Karu, Nasarawa State, Nigeria

${ }^{2}$ National Hospital Abuja, Plot 132 Garki Central District, Abuja FCT, Nigeria

${ }^{3}$ United State Department of Defence, Walter Reed Program-Nigeria, US Embassy, Abuja, Nigeria

${ }^{4}$ Defence Reference Laboratory Asokoro, Abuja, Nigeria

${ }^{5}$ University of Abuja, Nigeria

DOI: $10.36347 /$ sjams.2020.v08i09.011

| Received: 01.06.2020 | Accepted: 10.06.2020 | Published: 13.09.2020

*Corresponding author: Ajobiewe HF

Abstract

Original Research Article

Transmission of Helicobacter pylori is largely by the fecal-oral routes and considered as one of the major causes of peptic ulcer disease. Lack of proper sanitation, safe drinking water, and of basic hygiene, as well as poor diets and overcrowding, all play roles in determining the overall prevalence of the infection amongst patients attending National Hospital, Abuja. With their consent a total of 100 fecal samples were collected from patients and they were required to fill the questionnaire. Each fecal sample was tested using a Helicobacter pylori Ag rapid test cassette. Out of the 100 patients screened, 16 were found positive with the prevalence of $16 \%$. The male patients showed a higher prevalence with $20.5 \%$ in contrast to the female prevalence of $13.6 \%$. This data shows that the relatively low prevalence of this infection is as a result of the good living conditions and feeding habits of the patients.

Keywords: Peptic Ulcer Disease, Helicobacter pylori, Fecal -Oral Route, Patients.

Copyright @ 2020: This is an open-access article distributed under the terms of the Creative Commons Attribution license which permits unrestricted use, distribution, and reproduction in any medium for non-commercial use (NonCommercial, or CC-BY-NC) provided the original author and source are credited.

\section{INTRODUCTION}

The Helicobacter pylori is more common in developing countries such as Nigeria and its prevalence increases with age from $20 \%$ among teenagers to 50$60 \%$ of subjects in the 6 th and 7 th decades of life [1]. Infection rate of children in developing nations is higher than in industrialized nations, probably due to poor sanitary conditions, perhaps combined with lower antibiotics usage for unrelated pathologies. In developed nations, it is currently uncommon to find infected children, but the percentage of infected people increases with age, with about $50 \%$ infected for those over the age of 60 compared with around $10 \%$ between 18 and 30 years [2].

The higher prevalence among the elderly reflects higher infection rates in the past when the individuals were children rather than more recent infection at a later age of the individual [3]. Peptic ulcer disease may or may not have symptoms. Helicobacter pylori causes' peptic ulcer disease at first by infection, then it causes gastritis in the antral region and then there is a defective inhibition of gastrin release and acid secretion. The gastric acid is then hyper secreted and the duodenal acid load is increased. This is followed by metaplasia in the duodenal bulb, thus duodenal
Helicobacter pylori infection is caused [4]. Peptic ulcers can heal spontaneously and may occur intermittently and can also have a serious fate. The complications might be life threatening without any warning signs. This is most common in elderly patients on non-steroidal anti-inflammatory drugs (NSAIDs). Helicobacter pylori is a Gram negative, microaerophilic spiral shaped, flagellated, bacillus which colonize the mucus layer of the gastric epithelium and it causes more than $90 \%$ of duodenal ulcers and up to $80 \%$ of gastric ulcers [5]. Helicobacter pylori are associated with diffuse superficial gastritis and is one of the dominant causal factors for duodenal ulcer disease. The organism tests positive for oxidase, catalase and urease. Helicobacter pylori infection is common worldwide with prevalence rates ranging 30 to $40 \%$ in the United States, 80 to $90 \%$ in South America and 70 to $90 \%$ in Africa [6]. Although spirochetes have been described in gastric mucosa of humans since the early 1900, it was Robin Warren and Barry Marshall who in 1982 first characterized Helicobacter pylori and described its association with histologic gastritis and subsequent peptic ulcer disease [7]. Peptic ulcer disease also known as PUD is one of the most common ulcer which is a sore on the inner lining of the stomach or duodenum; the first part of the small intestine. Less 
commonly, a peptic ulcer may develop just above the stomach in the oesophagus. Peptic ulcers can be broadly classified into gastric or stomach ulcer and duodenal ulcer. Gastric ulcers occur mainly in the elderly, on the lesser curve. Ulcers elsewhere are often malignant. Duodenal ulcers are four fold commoner than gastric ulcer. It is identified by the most common symptom i.e. the epigastric pain occurs typically before meals or at night which is relieved by eating or drinking milk [8]. Another type of peptic ulcer disease is the Idiopathic Peptic ulcer disease (IPUD) is defined as a peptic ulcer without definite causes such as Helicobacter pylori infection, non-steroidal anti-inflammatory drugs (NSAIDs) use or hypergastrinemia. Peptic ulcer disease is an important cause of morbidity and mortality throughout the world affecting the lives of millions of people in their everyday life. In the United States, approximately four million people have peptic ulcers (duodenal and gastric), and 350,000 new cases are diagnosed each year. Around 180,000 patients are hospitalized yearly, and about 5000 people die each year as a result of peptic ulcer disease. The lifetime likelihood of developing peptic ulcer is about $10 \%$ for males and 4\% for females [9]. Complications of Peptic ulcer disease may include: internal bleeding, obstruction of food trying to leave the stomach, perforation and peritonitis. Helicobacter pylori cause chronic active, chronic persistent and atrophic gastritis in adults and children. Infected persons have a 2 to 6 fold increased risk of developing gastric cancer and mucosal associated-lymphoid-type (MALT) lymphoma compared with uninfected persons [10]. The genus Helicobacter pylori belongs to the subdivision of the Proteobacteria, order Campylobacterales, family Helicobacteraceae. This family also includes the genera Wolinella, Flexispira, Sulfurimonas, Thiomicrospira, and Thiovulum; the genus Helicobacter consists of over 20 recognized species, with many species awaiting formal rendition [11]. Members of the genus Helicobacter are all microaerophilic organisms and in most cases are catalase and oxidase positive, and many but not all species are also urease positive [12].

\section{METHOD}

A total of 100 samples were collected for this research. In the present study, adult patients with ulcer or suspected ulcer who were being managed in National hospital were analyzed. The sample collection included both male and female patients who were registered in the hospital microbiology department. Completely randomized enrollment and full consent of participants were sought before they participated in the study. The samples were screened for the presence of Helicobacter pylori. Stool samples were collected in sterile containers. Socio-demographic data were obtained through questionnaires. In this work, the Aria H. pylori Ag rapid test kit was used for the analysis; whose principle was based on lateral flow chromatographic immunoassay.

\section{RESULT}

A total of 100 patients were screened, of these; 16 were positive to Helicobacter pylori giving a prevalence rate of $16 \%$ (16/100). Table 3.1 shows the prevalence rate of Helicobacter pylori with respect to sex of the patients in the study population. The infection rate was highest among the females, 9 out of 66 (13.6\%) tested positive for Helicobacter pylori in contrast to the infection rate among the males where 7 out of $34(20.5 \%)$ tested positive to Helicobacter pylori. Table 3.2 shows the prevalence rate of Helicobacter pylori with respect to the different age ranges where patients in the age group 76-85 had the highest rate of prevalence of $30.8 \%$ while the age group 36-45 had the lowest rate of prevalence with $7.1 \%$. Other age groups $15-25, \quad 26-35,46-55,56-65$ and $66-75$ had the prevalence rates of $13.0 \%, 11.1 \%$, and $18.2 \%, 27.3 \%$ and $10 \%$ respectively. Table 3.3 shows the prevalence rate of patients who previously had ulcer where patients in the age group 66-75 had the highest rate of prevalence with $80 \%$ while the age group 26-35 had the lowest rate of prevalence with $33.3 \%$. Other age groups $15-25,36-45,46-55,56-65$, and $76-85$ had the prevalence rates of $39.1 \%, 42.9 \%, 54.5 \%$, and $69.2 \%$ respectively.

Table-3.1: Prevalence of Helicobacter pylori in relation to sex among patients attending National Hospital, Abuja

\begin{tabular}{|l|l|l|l|l|}
\hline Sex & Number screened & Number positive & Number negative & Percentage ratio (\%) \\
\hline Male & 34 & 7 & 27 & 20.5 \\
\hline Female & 66 & 9 & 57 & 13.6 \\
\hline Total & 100 & 16 & 84 & \\
\hline
\end{tabular}

Table-3.2: Prevalence of Helicobacter pylori in relation to age among patients attending National Hospital, Abuja

\begin{tabular}{|l|l|l|l|l|}
\hline Age (Ranges) & Number screened & Number positive & Number negative & Percentage ratio (\%) \\
\hline $15-25$ & 23 & 3 & 20 & 13.0 \\
\hline $26-35$ & 18 & 2 & 16 & 11.1 \\
\hline $36-45$ & 14 & 1 & 13 & 7.1 \\
\hline $46-55$ & 11 & 2 & 9 & 18.2 \\
\hline $56-65$ & 11 & 3 & 8 & 27.3 \\
\hline $66-75$ & 10 & 1 & 9 & 10 \\
\hline $76-85$ & 13 & 4 & 9 & 30.8 \\
\hline
\end{tabular}




\begin{tabular}{|l|l|l|l|l|}
\hline Total & 100 & 16 & 84 & \\
\hline
\end{tabular}

Table-3.3: Prevalence of patients who previously had ulcer

\begin{tabular}{|l|l|l|l|l|}
\hline Age (Range) & Number screened & Number of yes & Number of no & Percentage ratio (\%) \\
\hline $15-25$ & 23 & 9 & 15 & 39.1 \\
\hline $26-35$ & 18 & 6 & 10 & 33.3 \\
\hline $36-45$ & 14 & 6 & 9 & 42.9 \\
\hline $46-55$ & 11 & 6 & 5 & 54.5 \\
\hline $56-65$ & 11 & 5 & 6 & 45.5 \\
\hline $66-75$ & 10 & 8 & 2 & 80 \\
\hline $76-85$ & 13 & 9 & 4 & 69.2 \\
\hline Total & 100 & 49 & 51 & \\
\hline
\end{tabular}

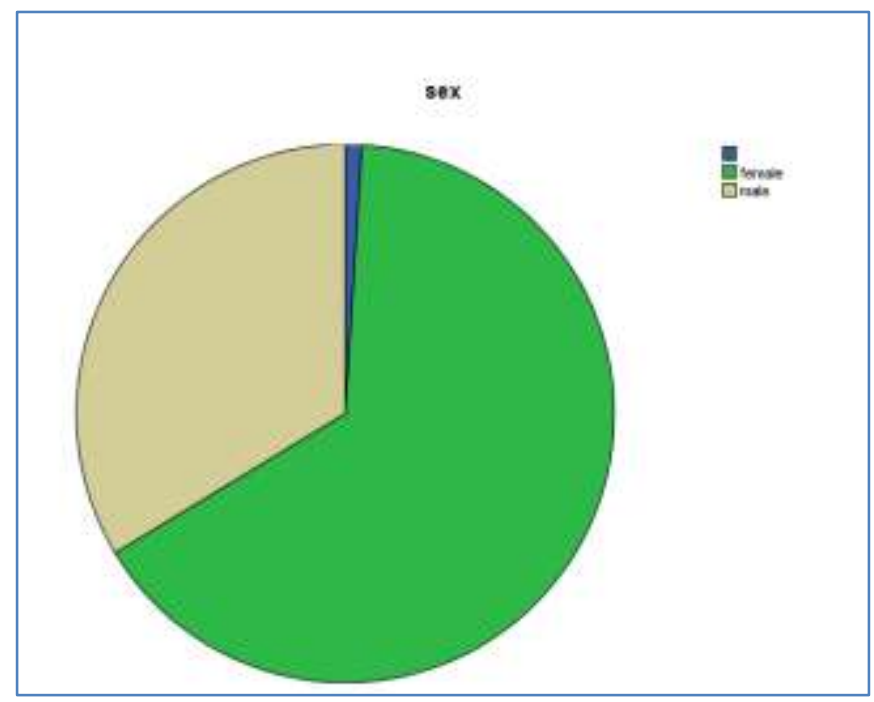

Fig-2: Prevalence of Helicobacter pylori in relation to sex among patients attending National Hospital, Abuja

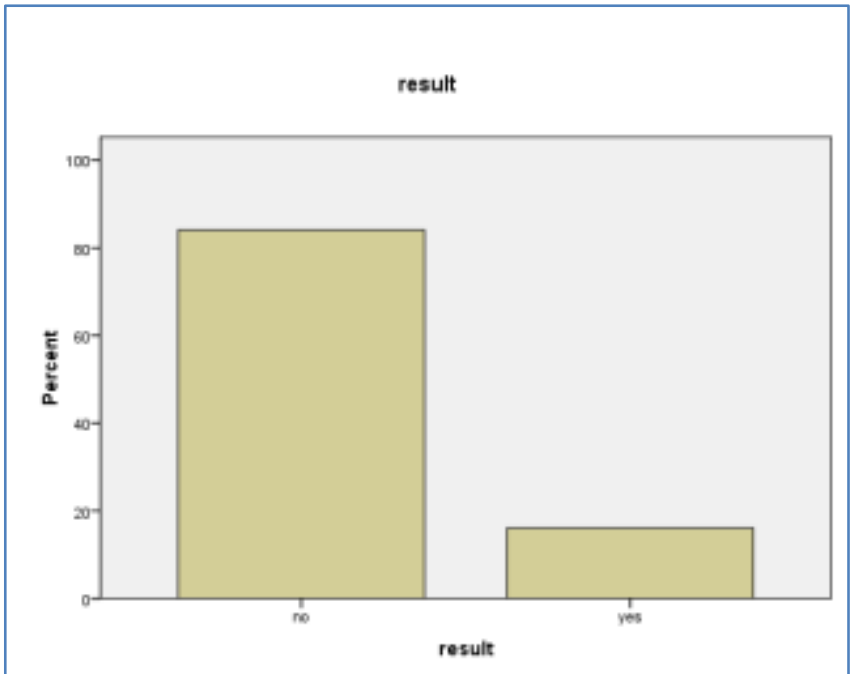

Fig-3: Prevalence of Helicobacter pylori in relation to test result among patients attending National Hospital, Abuja

\section{DISCUSSION}

The result of this study revealed that the faecal-prevalence rate of Helicobacter pylori among patients of National Hospital Abuja was 16\%. The detection of Helicobacter pylori using antigen or PCRbased methods directly from clinical samples might be non-specific due to cross reactivity. These limitations could have affected estimates of the prevalence of
Helicobacter pylori infection in previous studies. The result of this study was dissimilar to studies carried out in the Netherlands with low prevalence of $1.2 \%$, and Canada with $7.1 \%$ [13]. Our result here, however, was lower to those obtained in other areas such as Asia; Bangladesh (>90\%), India (88\%), Japan (70\%), the Middle East; Libya (94\%), Saudi Arabia (80\%) and Egypt (90\%), and South America; Chile (70\%), Brazil $(82 \%)$ were positive for Helicobacter pylori [11] shows 
a higher prevalence in contrast to this study. Also comparing this result to the works done in some parts of Africa, it was deduced that the result was lower; Ethiopia which had the prevalence of $96 \%$ [11]. Gambia with the prevalence of $80 \%$ and Ivory Coast with the prevalence of $65 \%$ (Holcombe 1992); Zimbabwe and Kenya showed a prevalence of $80 \%$ in both countries [13]. Our value was also lower than those obtained in other parts of Nigeria too. For instance, the work done by [62] in Kwara with a prevalence of $88 \%$. This low prevalence might be due to the exposure of the patients to the relatively fair hygiene of their environment.

\section{Conclusion}

This work was done using the faecal method to check the prevalence rate peptic ulcer caused by Helicobacter pylori in patients attending National Hospital, Abuja, and from the screening carried out it was discovered that there is a relatively low prevalence (16\%) of peptic ulcer caused by Helicobacter pylori within National Hospital, Abuja which may be attributed to the good sanitary living and good personal hygiene of the patients as well as regular checkups observed by patients. The low prevalence could also be related to the fact that other sources may cause infection that is; smoking, drinking of alcohol, Non-steroidal Anti Inflammatory drugs (NSAID), untreated stress, regular fasting, some host factors such as gene polymorphism and immune response.

\section{REFERENCES}

1. Jemilohun AC, Otegbayo JA, Ola SO, Oluwasola OA, Akere A. Prevalence of Helicobacter pylori among Nigerian patients with dyspepsia in Ibadan. Pan African Medical Journal. 2010;6(1).

2. Pounder RE, Ng D. The prevalence of Helicobacter pylori infection in different countries. Alimentary pharmacology \& therapeutics. Supplement. 1995;9(2):33-9.

3. Kusters JG, Van Vliet AH, Kuipers EJ. Pathogenesis of Helicobacter pylori infection. Clinical microbiology reviews. 2006 Jul 1;19(3):449-90.
4. Sheila, E Crowe, MD, FRCPC, FACP, FACG, AGAF, Peptic Ulcer disease (Beyond the basics), October 2011, Available at: http://www.uptodate.com/contents/peptic-ulcerdisease-beyond-the-basics (Accessed: 13th July 2013).

5. Marshall BJ, Mc Gechie DB, Rogers PA. Campylobacter pylori infection and gastroduodenal disease. Medical journal. 1985; 142: 439 - 444.

6. Genta RM. After gastritis-an imaginary journey into a Helicobacter- free world. Alimentary Pharmacology \& Therapeutics. 2002 Jul;16:89-94.

7. Mitchell A, Silva TM, Barrett LJ, Lima AA, Guerrant RL. Age-specific Helicobacter pylori seropositivity rates of children in an impoverished urban area of northeast Brazil. Journal of clinical microbiology. 2003 Mar 1;41(3):1326-8.

8. Murray Longmore, Ian B. Wilkinson, Edward H. Davidson, Alexander Foulkes Ahmad R. Mafi, Oxford Handbook of Clinical Medicine, 8th edn., New York: Oxford University Press Inc.; 2010.

9. Kumar, Abbas, Fuasto. Robins and Cotran. Pathologic Basis of Disease. 7th edition. Elsevier Publications.2008; 797-847.

10. Hunt, RH. Helicobacter pylori: from theory to practice. Proceedings of a symposium. Medical journal. 1996; 100 (5A) supplement.

11. Akada, J, Shirai, M, Takeuchi, H, Tsuda, H, Nakazawa, T. Identification of the urease operon in Helicobacter pylori and its control by mRNA decay in response to $\mathrm{pH}$. Molecular microbiology. 2000; 36: 1071-1084.

12. Thomopoulos, K. C., Vagenas, K. A., Vagianos, C. E., Margaritis, V. G., Blikas, A. P., Katsakoulis, E. C., \& Nikolopoulou, V. N. (2004). Changes in aetiology and clinical outcome of acute upper gastrointestinal bleeding during the last 15 years. European journal of gastroenterology \& hepatology, 16(2), 177-182.

13. Zsikla V, Hailemariam S, Baumann M, Mund MT, Schaub N, Meier R, Cathomas G. Increased rate of Helicobacter pylori infection detected by PCR in biopsies with chronic gastritis. The American journal of surgical pathology. 2006 Feb $1 ; 30(2): 242-8$. 